\title{
NOTAS
}

\section{SOBRE LA INFLUENCIA DEL MAYA \\ EN EL ESPAÑOL DE YUCATTÁN*}

En diversas ocasiones he procurado mostrar que la influencia de las lenguas amerindias sobre el español general de México ha sido muy débil y superficial. A lo que alcanzo, tal influencia se reduce a lo siguiente:

En el dominio fonético, a la existencia de un fonema prepalatal fricativo sordo $/ \check{s} /$, presente sólo en voces indígenas -como mixiote o xocoyote- y de rendimiento fonológico mínimo - [šišî] 'jabón vegetal' o [šáles] 'zurrapas de frituras del cerdo'--; al sonido dentoalvelar africado sordo [ŝ], que aparece exclusivamente en topónimos y antropónimos como alófono de $/ \mathrm{s} /$-Tzintzuntzan, Pátzcuaro o Quetzalcoatl-; y a la articulación explosiva de / $/ \mathrm{t}$ seguida de /1/ -tlapaleria, ixtle-, realizada ya como combinación de dos fonemas existentes en español, pero no como conservación del fonema nahua originario lateral africado sordo $/{ }^{\prime} /{ }^{1}$.

En el terreno gramatical, la influencia indoamericana sobre el castellano normal de México se reduce a la existencia de un sufijo -eco empleado en la derivación de gentilicios -yucateco, chiapaneco, guatemalteco, etc.-, que no cabe confundir con otro sufijo -eco, designador de defectos físicos o morales, de origen indudablemente liispánico, presente en palabras como patuleco o cacareco ${ }^{2}$. Acaso también fuera posible atribuir a la influencia indígena la presencia en el español de México, de un sufijo -i/ $n /$ che, despectivo (cf. metiche, pediche, etc.), pero es hipótesis que habría que analizar con mucho cuidado.

$Y$ en el dominio lexicológico, el más frecuentemente invocado por los indigenistas como prueba incuestionable de la fuerte interferencia de las lenguas amerindias en el español mexicano, la influencia se limita a tres centenares de palabras -incluyendo en esa cifra lexemas y vocablos derivados - de muy diversa vitalidad y de baja incidencia en el discurso (menos del $0.1 \%$ de promedio $)^{3}$.

* Esta breve comunicación fue leída en la reunión "Exploratory Workshop on Spanish in Contact with other Languages in the Western Hemisphere", celebrada en la ciudad de Nueva York del 7 al 9 de junio de 1978 bajo los auspicios del Social Science Research Council y la coordinación del Dr. Eugenio Chang-Rodríguez. Como no parece posible que se lleguen a publicar las Actas de esa reunión, me animo a sacar a la luz aquí mi modesta contribución, por considerar que, siendo tan escasos los estudios dedicados hasta ahora al español de Yucatán, cualquier ensayo, por modesto que sea, podrá contribuir en algo al mejor conocimiento de una modalidad de la lengua española tan singular e interesante como la yucateca.

1 Cf. "La influencia del sustrato en la fonética del español de México", RFE, 50 (1967), 145-161.

2 "Sobre el origen del sufijo -eco como designador de defectos", en Sprache und Geschichte. Festschrift für Harri Meier zum 65. Geburtstag, München, 1971, pp. 305-312.

3 Cf. mi librito sobre el Léxico indígena en el español de México, El Colegio de México, 1969; 2a. ed., México, 1979. 
Todo lo dicho hasta aquí se refiere a la influencia del sustrato indoamericano en el español normal de la ciudad de México.

Pero las cosas cambian mucho si la atención se enfoca sobre las zonas en que español y lengua amerindia conviven todavía hoy en boca de los mismos hablantes. Esto es, si se atiende a situaciones de adstrato - no de sustrato- referidas a las hablas regionales del interior del país. En ellas, las influencias de las lenguas indígenas se deja sentir con mucho mayor vigor ${ }^{4}$, aunque en grado muy variable según sean las condiciones históricas y socioculturales prevalecientes en cada zona. Innecesario parece recordar aquí que el grado de penetración de una lengua autóctona sobre otra invasora dependerá -entre otras cosas, pero sobre todo- de la vitalidad que haya conseguido mantener y del prestigio sociocultural de que disfrute. Ello ha sido muy bien advertido y señalado por Bertil Malmberg cuando explica las diferencias lingüísticas existentes entre unos y otros países de Hispanoamérica, y las hace depender,fundamentalmente, de las diversas condiciones culturales y sociales en que se han mantenido las lenguas en contacto con el español desde la época colonial hasta nuestros días ${ }^{5}$.

Dentro de la extensa geografía dialectal de México, una región se señala acusadamente frente a las demás y se singulariza por la muy particular situación lingüistica en que se encuentra: la península de Yucatán. Castellano y maya conviven todavía hoy en esa región, cuyo índice de bilingüismo es el más alto de todo el país. Y lo que resulta ser todavía más importante: la lengua maya goza en esa región de un prestigio que ninguna otra lengua autóctona alcanza a igualar en toda la República Mexicana. En Oaxaca, por ejemplo, el número de hablantes de lenguas indígenas acaso sea proporcionaimente tan elevado como en Yucatán; pero ninguno de los idiomas autóctonos de Oaxaca goza del prestigio social de que disfruta el maya en Yucatán. Además, el número de lenguas amerindias que se hablan en el estado de Oaxaca es muy elevado, lo cual implica una gran fragmentación debilitadora; en cambio, la única lengua indígena de la Península de Yucatán es la maya, lo cual le proporciona, lógicamente, un vigor singular. A todo ello se debe que, dentro de México, el español yucateco sea la modalidad lingüística castellana más intensa y ampliamente coloreada por la lengua indígena con que mantiene contacto. Así lo prueban los resultados obtenidos hasta el momento de la amplia investigación que El Colegio de México respalda desde hace una década: la que se encamina a delimitar las zonas dialectales del país. De ella he dado noticia en otras ocasiones, lo cual me exime de hacerlo ahora aquí ${ }^{6}$.

Dados los límites propios de esta comunicación, presentaré a ustedes un panorama general de la situación lingüística que se advierte hoy en la península de Yucatán, a través de las encuestas que allí hemos hecho dentro de la investigación a que acabo de referirme. Es muy posible que el único mérito de estas páginas radique en el hecho de haber sido organizadas sobre materiales de primera

${ }^{4}$ Cf. Ángel Rosenblat (El casteliano de Venezuela: la influencia indígena, Caracas, 1958, p. 12): "En rigor, la mayor riqueza de voces indigenas no está en el habla general, sino en lo regional o local. . . Cada pueblo, cada caserio, tiene, para nombrar sus plantas, sus animales, sus enseres domésticos, una rica terminología, en gran partc de origen indígena". Cf. también, entre otros, GERHARD ROHLFS, "Influence des éléments authochtones sur les langucs romanes", cn Actes du Colloque de. . Langues Romanes, Bucarest, 1959, p. 244.

5 Cf. B. MALMBERG, L'espagnol dans le Nouveau Monde, Lund, 1948, así como los diversos ensayos reunidos en su libro Estudios de fonética hispánica, Madrid, 1965.

${ }^{6} \mathrm{Cf}$, en especial, "Dialectología mexicana y sociolingüística", $N R F H, 23$ (1974), 1-34, y "Las zonas dialectales de México", en la misma revista, 19 (1970), 1-11. 


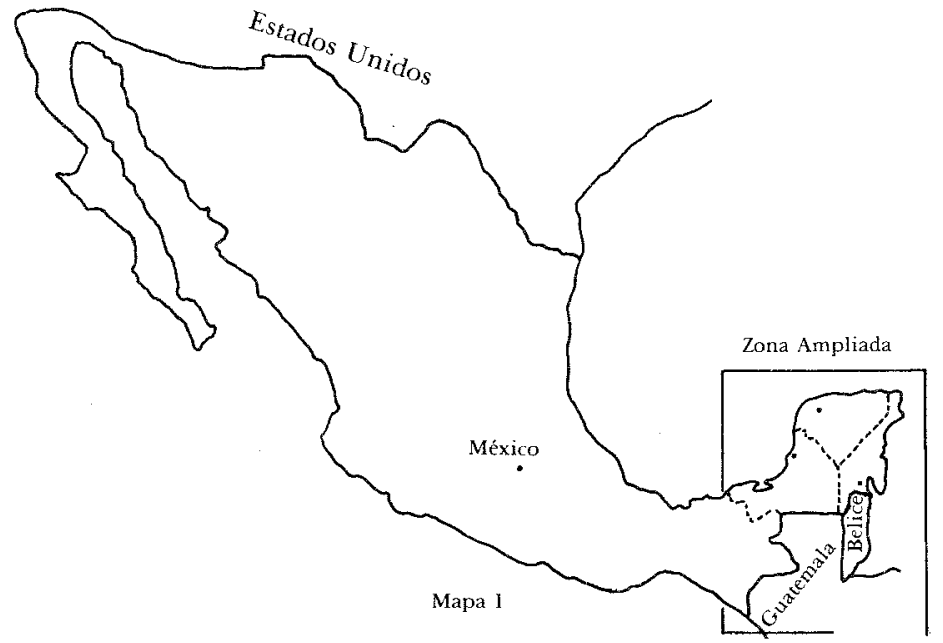

mano. Los datos que aquí presento están extraídos de los Cuestionarios aplicados en nueve localidades de la zona a tres o cuatro informantes de diverso nivel cultural, hombres y mujeres de diferentes edades ${ }^{7}$. Siendo absolutamente imposible atender a los pormenores condicionados por los tres factores socioculturales señalados - hacerlo exigiría de un espacio muy superior al que se me ha concedido-, presentaré los resultados de nuestras encuestas en su conjunto, como una visión global del estado de cosas prevalecientes hoy en Yucatán. Al fin y al cabo se nos ha dado oportunidad para que nos reunamos aq̣uí con el objeto de hablar en torno al español en contacto con otras lenguas, y no a las cuestiones particulares que una visión sociolingüística exigiría.

De las mil preguntas que integran el Cuestionario utilizado, 350 son de carácter lexicológico. Sólo de ellas me he servido para preparar estas observaciones. No obstante lo reducido de su número, proporcionan abundante información lingüística, y no sólo léxica, sino también fonética.El dominio sintáctico queda, naturalmente, al margen de la información que se obtiene a través de las respuestas concisas, generalmente unimembres, provocadas por las preguntas incluidas en un cuestionario. A pesar de todo ello, los materiales lingüísticos así reunidos bastan para confirmar la excepcional singularidad del español yucateco.

En el terreno fonético cabe anotar, ante todo, la existencia de una serie reducida de fonemas de origen maya que se han ido incrustando en el sistema fonético castellano de buen número de los informantes: el prepalatal fricativo sordo

7 Las poblacioncs estudiadas han sido Chctumal y Felipe Carrillo Pucrto, estado de Quintana Roo; Valladolid, Tizimín, Mérida y Ticul en el estado que hoy conserva cl nombre de Yucatán; y Campeche, Champotón y Mamantel en el estado de Campeche. En todas ellas hemos cubicrto cl Cuestionario con tres informadores, salvo cn Valladolid, Mćrida y Campcche, donde entrevistamos a cuatro personas en cada localidad. En total, me sirvo aquí de los datos lingüísticos proporcionados por 30 informantes. Las encuestas fueron hechas por Josefina García Fajardo, Antonio Alcalá Alba, Gustavo Cantero Sandoval, José Moreno de Alba y Juan López Chávcz, investigadores de El Colegio de México, sin cuyo concurso y admirable dedicación no hubiera sido posible emprender el proyecto de delimitación de las zonas dialectales de México, que se ha convertido ya $\mathrm{cn}$ la base del Atlas lingúístico general del español mexicano. 


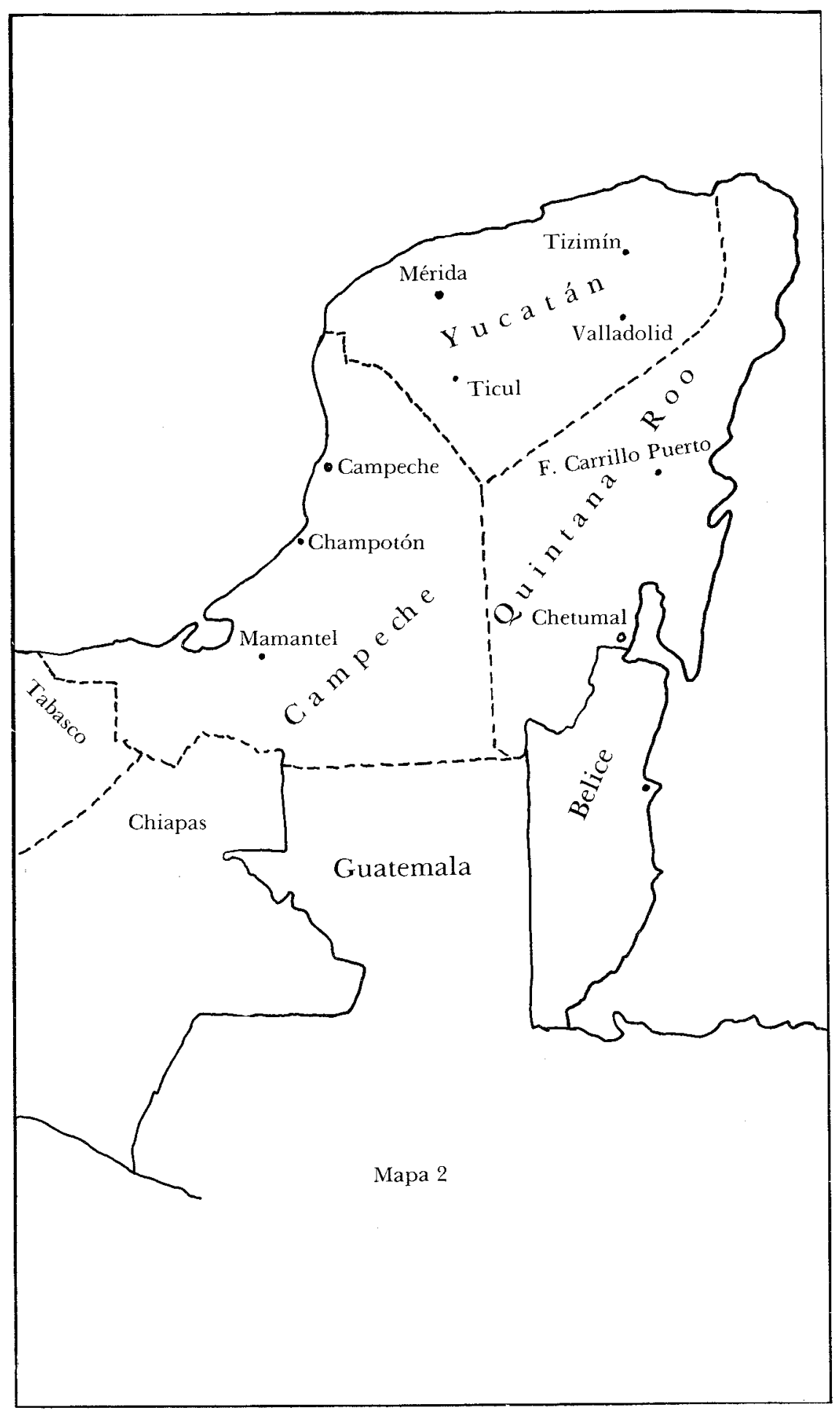


$\mid \check{s} /$ de voces como šet o šoi; el dentoalveolar africado sordo /s/ de sagwayak, por ejemplo; el aspirado laríngeo $/ \mathrm{h} /$ de $\hat{c} u h u ́ m$; y la oclusión glotal $/ ? /$, que entra en combinación con vocales (bo?, ka?l, nené?) o consonantes (paĉ? ok, cik ?im, khap? $)^{8}$.

Llama también poderosamente la atención el alto número de fonemas consonánticos que pueden aparecer en posición final de palabras en voces procedentes de la lengua maya, frente a lo que sucede en voces de origen español: $-s$ (en $t u$ -

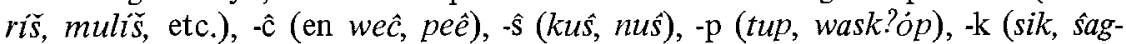
wayák), -m ( $\hat{c} e m)$, -t (šet). La palatal fricativa sorda es silábica en palabras como štup, de uso general en el español de Yucatán.

Cierto que, en algunos casos, las voces mayas que se han incrustado en el español yucateco han modificado un tanto su fisonomía para adaptarse al sistema fonético castellano. Así turǐs despalataliza a veces su fonema final y se transforma en turis (un informante de Ticul); y set toma en ocasiones una $-e$ final, con lo cual su terminación se castellaniza en šete (informante de Mamantel). Pero lo más común es que la voz maya, al pasar a formar parte del sistema léxico español, conserve la estructura fonética indígena en toda su pureza.

La interferencia lingüística resalta más, por lo menos cuantitativamente, en el dominio del léxico. Los 350 conceptos previstos en el Cuestionario han proporcionado un total de 50 voces de origen maya en las respuestas obtenidas, lo cual resulta ser un porcentaje extraordinariamente elevado ${ }^{9}$, que no creo que pueda repetirse en ninguna otra región dialectal de México. Claro está que no todas esas voces revelan la misma vitalidad, ni mucho menos. Algunas de ellas son de uso general en toda la zona y entre todos los hablantes yucatecos de español; otras fueron recogidas en boca de sólo uno o dos de nuestros informadores. Aproximémonos un poco a ellas.

No son escasas las voces de uso general o casi general en todas las poblaciones de la zona estudiadas: Para designar a la'libélula' (cuestión 659), la casi totalidad de nuestros informadores emplearon la voz maya turiš o $t u h \widetilde{s}^{10}$, en la gran mayoría de los casos como forma única; sólo tres de ellos invocaron además, paralelamente, la forma libélula y dos más se sirvieron, junto al mayismo, de la designación caballito del diablo. Otras voces de difusión igualmente general son: huech (pronunciada [wéĉ] o [gwéĉ], designación maya del 'armadillo'; xoy [šoi] 'orzuelo', que en el estado de Campeche alterna con el término, también maya, tutupiche; [mulîs] = (pelo) 'rizado'; xic [šik] 'axila, sobaco'; chuchuluco 'chichón', de etimología controvertida, pero muy probablemente maya; sosquil, usado casi umiversalmente en el sentido de 'estropajo' (cuestión 944) y algo menos generalmente en el de 'ixtle' (fibra; cuestión 871); bacal, acaso el mayismo

8 Determinar si se trata, en cste último caso, de consonantes verdaderamente glotalizadas -comunes en la lengua maya - o de secuencias fónicas - corte glotal toclusión oral-es tema delicado $\mathrm{c}$ importante, que requiere de un estudio aparte y más pormenorizado, el cual espero poder realizar en un futuro próximo. Tratándose de voces mayas, cabe admitir que sean verdaderos fonemas glotalizados ( $p^{\prime}$ t' $\hat{c} K^{\prime}$ ), pero tal vez no suceda lo mismo cuando se trate de palabras cspañolas, en cuya articulación más cabe suponer secuencias del tipo [?p $2 \mathrm{t}$ 2K].

9 No incluyo en esta cifra, naturalmente, otros muchos indigenismos, de diverso origen nahua, por lo general - que son usuales en el español general de otras zonas del país, como jicara, elote, mecate, maguey, zopilote, molcajete, etc. Los 50 términos que considero aquí son mayismos peculiares del español hablado en Yucatán.

${ }^{10}$ La variante con $/ \mathrm{r} /$ parece ser la propia del estado de Yucatán; la variante tulís se recogió en Campeche, y se extiende también por el estado de Tabasco. (Cf. Francisco J. Santamaría, Diccionario de mejicanismos, Méjico, 1959, s.v.). 
más unánimemente empleado en toda la península yucateca, por 'olote, zuro'; $x i x$ [šiš], designación casi tan general como la anterior, tanto con el sentido de 'migajas' (cuestión 884), como con el de 'posos, asientos de un líquido' (c. 885); y tup o [štúp], también voz prácticamente única en Yucatán para designar al 'benjamín, hijo menor'.

De uso algo menos generalizado - de acuerdo con nuestras encuestas, por lo menos- pero de cualquier modo notablemente intenso en el español yucateco son otras voces mayas, como xet [šet], designadora del 'labio leporino'; xux [ššs], empleada ampliamente para designar a la 'colmena' (c. 669) y en menor medida a la 'avispa' (c. 673); chem, pronunciada normalmente [šem] o en menor medida [cem], por 'legaña'; chuchú o chucho, voz maya de probable origen onomatopéyico, usada por nuestros informantes para designar ora la 'ubre' de la vaca (c. 694), ora su 'pezón' (c. 695), ora -más generalizadamente- el 'pezón' de la mujer (c. 696), en cuyo caso puede adquirir la forma diminutiva, chuchito; para referirse a la 'res sin cuernos' (c. 692), muchos de nuestros informantes dijeron [wolpól], [gwolpól] o [bolpól], variantes de un término de origen maya constituido en torno a poi 'cabeza'; y finalmente, con el sentido de 'coscorrón' (c. 829), los informantes del estado de Yucatán -no los de Quintana Roo ni Campeche-emplearon las formas [wask?óp] y [gwask?óp], de origen maya ${ }^{11}$.

De aparición mucho menos sistemática, pero reveladora también de la profunda interferencia del maya en el español de Yucatán, son otras muchas voces documentadas en nuestros cuestionarios. Con el objeto de no colmar su paciencia, me limitaré a enumerar algunas de ellas: chichimbacal, nombre de un pajarito que nuestro informante confundió con el 'gorrión' (c. 654); tucha 'pantorrilla', probablemente del maya tuch 'ombligo', pero usado también para designar cualquier protuberancia (cf. Santamaría, Dicc.); chuchul -o también [šušulíto]aplicado a la piel 'arrugada' (c. 828); pech, usado en Valladolid por 'garrapata'; [šot], empleado en Champotón por 'musgo'; [xoĉ́o, respuesta de varios informantes para el concepto 'gorrón', etc.

Advertía líneas atrás que las voces de procedencia maya solían conservar su estructura fonética originaria al pasar a formar parte del vocabulario español de la zona. Creo que esto es sumamente significativo: el bilingüismo de muchos yucatecos es tan completo y vigoroso, que los sistemas fonéticos del maya y del español se confunden a veces, en algunos de ellos, en un solo sistema común, que emplean casi indistintamente o poco menos, al hablar una u otra lengua. Así, hablando castellano, no dejan de usar la oclusión glótica /?/ tan común en maya (no?, nené?), ni se sienten obligados a castellanizar la terminación consonántica de las voces mayas que han trasplantado al español ( $p a \hat{c} ? o k$ 'empeine', $\hat{c}_{i k}$ ' $i m$ 'larva de la garrapata', šuš 'colmena', etc.), ni tienen reparo alguno, en cambio, en fortalecer el elemento velar del fonema labiovelar maya $/ \mathrm{w} /$, de acuerdo con la tendencia común del castellano, diciendo así [gwéĉ] por [wéĉ]. Parece haberse producido, en tales casos, un sorprendente sincretismo de los dos sistemas fonológicos, fenómeno que inútilmente buscaríamos quizá en el resto de las modalidades dialectales del español mexicano.

Claro está que, en no pocas ocasiones, los términos mayas se han adaptado más o menos plenamente al sistema fonomorfológico del castellano. Pero ello

11 Cf. A. BARRERA VÁSQUEZ (director), Diccionario maya Comermex, Mérida, 1981: “Was k' op: pescozón" (p. 913a).K'op significa, por sí mismo, 'coscorrón' (cf. id. p. 413b); wak' es 'reventar, explotar, estallar'. 
también de manera que parece comprobar ese extraño sincretismo. La voz tulǐs, por ejemplo, se castellaniza - parcialmente- en Champotón recibiendo una - e final que evita la terminación en -š ajena al español, pero mantiene en su pureza originaria a esa palatal fricativa, extraña hoy en nuestro idioma; resulta así el híbrido tuliše. De semejante manera, el mayismo štup se integra en el sistema morfológico castellano mediante la adopción del morfema diminutivo -ito, pero mantiene a la vez su estructura fonológica mayense, y el resultado es otro híbrido notable: śtupito. Paralelamente, en el caso de chuchul 'arrugado', alternan las formas [ĉuĉúl] y [šušúl] con los morfemas hispánicos de plural o de diminutivo: [šuśúles], [ĉuculítos], etc. Siendo tuch 'pantorrilla' palabra de género femenino, adquiere fácilmente el morfema femenino del castellano, $-a$, y se transforma en tucha. Por usarse normalmente en forma plural, el término maya chem 'legaña' se pluraliza a la castellana en chemes.

La mayor parte de estos mayismos alterna, en el habla yucateca, con otras designaciones de origen hispánico o también amerindio. Así xoy [šói], por ejemplo, alterna en algunos de nuestros informantes con orzuelo y perrilla; chuchuluco, con el español chichón y con el náhuatl chipote; chic [ĉik], con sobaco o axila. Pero lo interesante y sintomático es advertir que esas concurrencias no se dan sólo en el habla de los informantes incultos o de menos instrucción escolar, sino que alcanzan también al idiolecto de los hablantes de alto nivel cultural. No son, pues, los mayismos peculiaridad del habla vulgar o rural de la zona yucateca, sino rasgos lingüísticos propios del sistema comunicativo común a toda una región dialectal. En esto la lengua maya difiere fundamentalmente de los otros idiomas autóctonos de México: su empleo alcanza los niveles culturales superiores de la sociedad. De ahí, su singular prestigio, inigualado por las restantes lenguas aborígenes del país. Y de ahí su superior capacidad de interferencia respecto del castellano. Algunos de los mayismos recogidos en nuestros cuestionarios se obtuvieron de boca, precisamente, de los hablantes más cultos: [kuŝ] 'pavo', en el hablante más instruido de Carrillo Puerto; [peĉ] 'garrapata', en un profesor de Valladolid; [čik], [šuš] y [štup] en un abogado de Mérida, así como en un profesionista universitario de Campeche. $Y$ en no pocas ocasiones la respuesta que obteníamos en primer lugar, más espontáneamente, era la correspondiente a la forma maya; sólo después, dicha ya la voz indígena $-y$ acaso por reacción cultista provocada por la situación un tanto artificial propia de toda encuesta-, añadía el informante el sinónimo de origen castellano: xix solía preceder a asiento; chuchuluco a chichón y a chipote; muliśs a rizado, etc.

El bilingüismo característico de gran parte de la actual población yucateca contribuye, si no me equivoco, a intensificar el polimorfismo del castellano hablado en la región. Todo el español mexicano es acusadamente polimórfico, pero el fenómeno se agudiza en las zonas bilingües, como es Yucatán. Ahí, un mismo hablante puede emplear, dentro del mismo discurso, unas veces las formas "glotalizadas", y otras, las variantes normales, sin corte glotal; unas veces, el término hispánico, y otras, la voz maya correspondiente. El polimorfismo relativo a los fonemas vibrantes es particularmente intenso en el español yucateco, en el cual alternan libremente - casi caprichosamente - las articulaciones vibrantes oclusivas $/ \mathrm{r} / \mathrm{y} / \overline{\mathrm{r}} /$, con las fricativas $/ \mathrm{x} / \mathrm{y} / \underline{\mathrm{x}} /$, con las asibiladas sonoras $/ \tilde{\mathrm{r}} / \mathrm{y}$ $\overline{\overline{\mathrm{r}}} /$ o ensordecidas $/ \tilde{\mathrm{r}} /$ y $/ \overline{\bar{r}} /$, y aun con la retrofleja $/ \mathrm{r} /$, de manera que una perso-

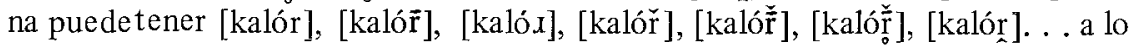
largo de una misma encuesta. Y este acusado polimorfismo del español yucateco creo que se debe, no tanto a la influencia indígena directa, sino a la influencia 
indirecta, que consiste en la debilitación de la norma como resultado de la particular situación que mantienen dos lenguas en contacto ${ }^{12}$.

Con lo dicho, considero que queda suficientemente evidenciada la singular situación de privilegio de que la lengua maya goza, respecto del castellano y dentro de su particular marco geográfico, en comparación con las demás lenguas indígenas de México $^{13}$. Sólo en otras regiones muy alejadas podríamos hallar una situación igualmente privilegiada, y tal vez sólo en un país - el Paraguaygoce la lengua autóctona de mayor vigor y prestigio del que disfruta la lengua maya en Yucatán. Prestigio y vigor que coloca al castellano en una situación muy especial de verdadera coexistencia con otra lengua, y dentro de niveles muy semejantes o relativamente aproximados. Esta peculiar situación es campo abonado para investigaciones lingüísticas -dialectales y sociolingüísticas- de extraordinario interés. Por desgracia, nadie se ha interesado todavía por iniciar esas provechosas investigaciones de manera sistemática ${ }^{14}$. La filología hispanoamerindia sigue aún en pañales.

JUAN M. LOPE BLANCH

Universidad Nacional Autónoma de México.

12 Cf. mi estudio sobre "Algunos casos de polimorfismo fonético cn México", RDTP, 32 (1976), 247-262, y el artículo sobre "Un caso de posible influencia maya en el español me. xicano", NRFH, 24 (1975), 89-100, en especial p. 99.

13 De la personalidad u originalidad del español yucateco me he ocupado no hace mucho; cf. "El léxico de la zona maya en el marco de la dialectología mexicana", $N R F H$, $20(1971), 1-63$.

14 El conocido libro de VÍCTOR M. SUÁREZ, El español que se habla en Yucatán, Mćrida, 1945 (2a. cd., Mérida, 1979), es obra de carácter general y poco sistemática en sus análisis. Y es la única de que disponemos hasta ahora. 